\title{
WHAT YOU TOUCH IS (NOT) WHAT YOU SEE. THE HAPTIC UNCONSCIOUS AND DIGITAL IN-CORPOREALITY IN THE AIRPORT SPACE
}

\begin{abstract}
There we no longer have any secrets, we no longer have anything to hide. It is we who have become a secret, it is we who are hidden, even though we do all openly, in broad daylight.
\end{abstract}

Gilles Deleuze, Claire Parnet, Dialogues II

\begin{abstract}
The contemporary airport features a wide array of convergent apparatuses that digitize various services, thus modifying the space and creating unique experiences to travelers. Their increasingly haptic interfaces make techno-sensation emerge as of pivotal importance to comprehend the deeper cultural transformation animated by computational apparatuses. This process engages our bodies that constitute a material resource and feed the realm of digital data. As a perceptual machine, airport terminal shapes our sensations and works our feelings but its expanding codespaceassuming haptic image - engenders a novel mode of extra-perceptual experience. Adopting a new materialist and realist approach to computational media inspired by Gilles Deleuze and Gilbert Simondon, this article explores how airport environment is articulated in a techno-intimate manner, and how this transforms our habituated, representational, mode of organizing visual and haptic experience. Taking cues from Walter Benjamin and Cubist art, it further addresses aesthetic-ecological questions about our intimacies and the manners they are spatially architected by haptic interfaces. Critically engaging with the example of "The Social Tree" at Changi Airport, Singapore, the article demonstrates how the sensory machines codify travelers' bodies, thus triggering their becoming-imperceptible. Analyzing airport's generation of sensation beyond receptivity, this article accounts for how sensory entanglement with haptic interfaces $\mathrm{s}(\mathrm{t})$ imulates emergence of an in-corporeal aesthetic — one that no longer rests on distancing vision but (cod)entangled, sensible screen-series.
\end{abstract}

Keywords: airport, codespace, Deleuze, haptic unconscious, in-corporeal, taktisch 


\section{Introduction}

Employing an immanent perspective, expressed in Gilles Deleuze's pronouncement that " $[\mathrm{t}]$ he point of critique is not justification, but a different way of feeling: another sensibility" (1983, p. 94), I will offer a meditation on what computing bodies can do. Consequently, in the following, I will explore not how the sensory media in the airport codespace ${ }^{1}$ reshape sensibility (determinism), nor how we modify (i.e. extend and/or enhance) our sensory capacities through media devices (functionalism, prosthetics), but how the sensory media in the airport codespace constitute an absorptive encounter of the sensorium and the code, generative of new modes of in-corporeal, extra-perceptual, becomings. Following Steve Goodman's appeal to break with the dominant humanist tradition and its anthropocentric specter (2010), I will posit airport sentient technologies' operations and effects as indifferent to entrenched dichotomies (e.g. real/virtual), and imperceptible to and through representational and static modes of sense perception. Goodman states, "If we subtract human perception, everything moves. Anything static is so only at the level of perceptibility. At the molecular or quantum level, everything is in motion [...]" (ibid., p. 83). In the context of airports, this is evidenced by the growing presence of haptic apparatuses, which are adding sensory content to mediated communication, turning the (apparently) distant into present proximity. To do justice to this pervasive sensory interconnectedness within the intensive environment of airport codespace, I will rely on Arnold Berleant's approach that brings together a spatial aesthetic and an aesthetic ecology in order to analyze the realm of the sensible (Berleant 1997; 2010). I will examine just one concrete example of the sensory mediascape, a curious art installation-The Social Tree at Singapore Changi Airport_-and discuss the sensory workings of the haptic unconscious (of the code), and its environmental aesthetic of in-corporeality, all the while exposing the representational limits of both touch and vision.

The amount of spatially embedded and infrastructurally deployed computational microsensors that gather data for the sake of predictive analysis makes it legitimate to posit contemporary airport space as an environment of ubiquitous computing (Weiser 1991; Kasarda, Lindsay 2011; Mayer-Schönberger, Cukier 2013). The saturation of sensors and sentient apparatuses, the Internet of Things and Places as well as AR-equipped mobile apps together with computational networks and information infrastructures that connect them, seamlessly integrated into the airport terminal, engender an immanent codespace, materializing the agency of the environment in its own process of production, independent of its correlation with human sensibility. Re-

The term code/space was introduced by Rob Kitchin and Dodge Martin in their work Code/Space: Software and Everyday Life in 2011. Remaining in agreement with their definition of code/space as entirely dependent upon software for its production, I propose a different form of writing, i.e. codespace, which emphasizes their reciprocal entanglement and expresses an immanent and new materialist approach that I adopt in this article. 
ferring to tracking as a science of movement optimization, indispensable for airport space management, Jordan Crandall pointedly remarks,

All urban phenomena are categorized, standardized, and rendered interoperable within the analytical architectures and procedures of this strategic, calculative mobilization. It constitutes a defining horizon for the movements of the world - a sensory, cognitive, and calculative ambiance against which the phenomena of urban life are understood. ${ }^{2}$

Equipped with advanced sensing technologies as diverse as full-body scanner, thermal scanning, biometric self-service kiosks, touch-screen cameras, face recognition, real-time video conferences with airport crew, robots recognizing and responding to emotions, analyzing group behavior and reacting to unexpected situations, airport mobile apps, artistic, intermedia and interactive installations, airport media are able to sense the environment, insinuate into the body, glean data, compute and feed-forward it, beneath and thus regardless of (human) perception. This evidently undermines the traditional, negative construal of technology as sequestered from, and subservient to, humanity and makes it matter, as David Nye states, "because it is inseparable from being human. Devices and machines are not things 'out there' that invade life. We are intimate with them from birth, as were our ancestors for hundreds of generations" (2006, p. ix).

The increasing level of saturation of these sentient technologies makes the airport space both highly sensory and sensitive, which evokes David Howes' concept of "hyperaesthesia", that expresses a heightened sensuality inherent in the logic of late capitalism (2005), and Anna Munster's that of "an aesthesia of networks", which underscores the experiential - properly aesthetic — nature of networks and their capacity to germinate new environmental forms of sensibility (2013). The hyperaesthetic of airport space has increasingly relied on sensory media and software simulations that are used to augment practices, which monitor and regulate flows of bodies and objects at the airport, thus intensifying and heightening our digital airport experience. Assuming the form of a body-snatching simulacrum, ${ }^{3}$ airport's sensory media effectively draw embodiment away from its humanistic capture within a concept of the body as a bounded interiority by activating extensive and intensive becomings. In doing so, they subject sensibility to virtual extensions and simulacral multiplications. Technically, these apparatuses feed forward the sensory data into a near-future consciousness, which makes it_as Éric Sadin claims - essentially anticipatory (2011). Expanding on Michel Foucault's definition of apparatus, Giorgio Agamben renders it as "anything that has in some way the capacity to capture, orient, determine, intercept,

2 J. Crandall, "Summary of Gatherings", http://jordancrandall.net/main/+GATHERINGS/index.html accessed: 4 January 2019.

3 This is a metaphor Augé proposes to account for the "invasion of images" through which "the new regime of the imaginary [...] nowadays touches social life, contaminating it and penetrating it to the point where we mistrust it, its reality, its meaning and the categories (identity, otherness) which shape and define it" (Augé 1999, p. 2). 
model, control, or secure the gestures, behaviors, opinions, or discourses of living beings" (2009, p. 14). These software simulations do much more than offer predisposed actions that are learnt by exposing their users to the sorts of feelings and states they are likely to encounter (Budd, Adey 2009). Capturing the dimensions of environmental sensibility, inaccessible or prior to human consciousness, airport sensory apparatuses pre-cognitively feed the data forward for us to anticipate. ${ }^{4}$ Importantly, technical mediation is introduced into the phenomenal realm, which bears on the structure of experience in general, and radically alters its meaning. Reconstructing a cultural history of airport, Alastair Gordon observes that as flight increased in popularity in the second half of the twentieth century, "airportness" emerged as a "structure of feeling", and thus yielded a new phenomenology of perception - specifically intended for jet flight and promoting distinct architectural styles and interior designs (2004, pp. 170-171). No longer a surrogate for the perceptual flux of experience, nor a tool for recording that both enabled reproduction of experience and motivated delinking of human and machine, airport digital media cut right into, mediate and modulate not merely the subjective mode of sensation, but the entire environmental sensibility. In doing so, they amalgamate the electronic sense with flesh-sense, affecting the modes humans sense, perceive and act, engendering — as I will argue — an environmental aesthetic of in-corporeality.

\section{Haptic unconscious}

Devices that exploit haptics have been around for decades; many modern airplanes, for instance, have had haptic control columns that shake or vibrate to warn the pilot of an approaching stall. However, the surge and spread of sentient technologies has considerably intensified over the past decade, pervading the space of the terminal. As Eric Schmidt and Jared Cohen predict, "By 2025 the majority of the world's population will, in one generation, have gone from having virtually no access to unfiltered information to accessing all of the world's information through a device that fits in the palm of the hand" $(2013$, p. 4). Urban spaces are becoming more and more software-mediated and their development increasingly code-determined, which inevitably means that physicality is becoming more mutable by technology, and aereality ${ }^{5}$ undergoes optimization. It is worth remembering that the code is enfolded onto the body and the actual, and it is only by its intermediary nature - that the digital exists as a sensible fold - that it becomes creative at all. Already in the early 1990s, Derrick de Kerckhove observed, "The multisensory interactive systems of virtual reality are discovering the countless possibilities of the cutaneous senses. The problem is not

4 Interestingly, the term anticipation derives from Latin anticipatio (i.e. ante - before, capere - capture), which literally denotes preconception.

5 The concept was coined by Peter Adey to capture the currently central role of air-transport mobilities to contemporary societies (Aerial Life: Spaces, Mobilities, Affects, Oxford: Wiley-Blackwell, 2010). 
only the technical simulation of touch but also, importantly, new kinds of tactile experiences (1993, p. 152). The field of haptics has proven that touch extends our immersion in a virtual environment, making it (feel) more intense and solid (Paterson 2007, p. 133). However, the amount of digital sensors of various kinds that suffuse the contemporary airport environment shed a different light on the haptic interface and its role in the continuous generation of experience. The sensorium becomes distributed across media networks that broker its implication within the greater airport sensory environment, which I heuristically render in terms of haptic unconscious, and likewise approach hermeneutically.

In his seminal essay, The Work of Art in the Age of Mechanical Reproduction, apart from exploring the extensive and prosthetic function of the medium, Walter Benjamin emphasizes the disruptive (hence creative) potential of the medium's expansion and implication. In identifying the technologically induced unconscious of vision, he maps out the sensible processes captured by the eye of the camera, which will inevitably alter perception of reality. I follow Benjamin who posits the haptic unconscious in time, which reveals affective incorporeality as the body's capacity to experience itself as more than itself - extra-perceptually, thus deploying its sensorimotor power to experiment and create the unpredictable. This facilitates the body's extrapolation beyond itself, viz. body's becoming-imperceptible, its untouchability, as Jean-Luc Nancy puts it, "[...] the line that separates the touching from the touched and thus the touch from itself" $(2008$, p. 13), which instigates a play of boundaries between conscious perception and unconscious sensation. Clearly, the haptic unconscious moves beyond any isolated sense into a meshwork of machinic sensations, demonstrating that (representationally) established perception is a threshold and not a limit.

Benjamin's theory of the technologically produced unconscious of haptic sensation resonates well with Deleuze's transcendental empiricism, ${ }^{6}$ particularly as it unfolds on the computer-human body hybrid in the airport space. Consequently, the haptic unconscious implicates new modes of sensing and touching fueled by the sensory airport media. Rather than the unconscious of touching, the haptic unconscious expresses a body extended across space and viscerally enmeshed with the environment. Following Deleuze's and Guattari's critique of the psychoanalytic concept of the unconscious and of the social and political institutions that maintain the trenchant metaphysical binaries of subject - object, human - world, and that keep machine separate from being human, I will argue that the haptic unconscious as it operates in the airport environment is being produced through a haptic encounter in between bodies and technologies in a machinic manner (Guattari 2011). In consequence, being neither a theater for the figural representation of social fantasies, nor an impo-

6 Deleuze affirmatively accounts for sensation itself, the vital source of an intensive production of sensibility rather than a mere receptivity. Empiricism becomes transcendental when no transcendent mediation is allowed. 
sition of the bourgeois concept of the family onto the psychology of individuals, the unconscious is rather a site of production-immanent and intensive (Deleuze, Guattari 2004a). The virtuosic immersion and connectivity that the haptic unconscious expresses conceptually is difficult to render empirically as the "transparent and ubiquitous threshold becomes simultaneously invisible and inoperable" (Galloway 2012, p. 25). The problem, to paraphrase Deleuze and Guattari, is not that we have become too much mediated, but - quite to the contrary-we have not been mediated enough, ${ }^{7}$ so as to capture and ethologically assess the transformative potential of the sentient technologies' aesthetic involution, of which the airport is but one site. In my analysis of the selected example of airport sensory and interactive art, I will posit the haptic unconscious in a twofold manner. As a surface production par excellence, it is geared - in keeping with Benjamin's postulation - to articulating the taktisch $^{8}$ nature of the image that goes beyond the idea of haptic visuality, ${ }^{9}$ and disavows its substitutive function, and, second, to bypassing the long-standing dualism of transparent versus opaque in the airport codespace.

For the sake of the transparency of my analysis, given the semantic wealth of the concept of "touch" as well as its cultural being, this notion must be clarified before we proceed. Touch is our earliest sense to develop (Montagu 1986). It has evolved to work in a tight partnership with vision and hearing. Quite different, however, from sight and hearing, which appear less direct (and as such, traditionally have been coopted by representation), haptic sense $\mathrm{e}^{10}$ - counterintuitively at first sight — retains more distance and allows for a sensible interval in responding to the milieu's physical conditions and stimuli. ${ }^{11}$ This intermission is already ingrained in the etymology of the verb haptein, which in ancient Greek - as Jean-Luc Nancy reminds us - aside from

In their introductory chapter to A Thousand Plateaus, titled "Rhizome," Deleuze and Guattari, enlisting the main characteristics of the concept of rhizome, critique the various traditions of thought predicated upon linearity. Significantly, reviewing linguistic models, they expose their conceptual limitations: "Our criticism of these linguistic models is not that they are too abstract but, on the contrary, that they are not abstract enough, that they do not reach the abstract machine that connects a language to the semantic and pragmatic contents of statements, to collective assemblages of enunciation, to a whole micropolitics of the social field" (2004b, 8). Digital interfaces can be instructive in demonstrating an active, dynamic and multimodal nature of sensibility, hence a source of creation- different and still potentially richer than the digital code.

8 I pluck out the term from W. Benjamin's essay (1969) to critically engage with its double entendre in German, wherein taktisch translates as both tactile and tactical.

9 Noteworthy in this context is the critical observation made by Erkki Huhtamo about inadequacy of the term with regard to interactive art (2007, pp. 73-74).

10 Given the neurological richness and lexical and cultural complexity of the sense of touch, for the purposes of this article I will adapt the framework proposed by Mark Paterson who relates "haptic" "to the sense of touch in all its forms including proprioception, vestibular, kinaesthesia, cutaneous, tactile, force feedback" (2007, p. ix).

11 This is corroborated by a plethora of relatively recent research studies coming from such fields as fields of cognitive neuroscience and psychophysics, which provide empirical evidence that the sense of touch is far from being a direct mode of perceiving. See, for example, Gallace, Spence 2014. 
"able to lay hold of", also means "to hold back, to stop" (2008, p. 15), as well as being aptly illustrated by the musical form of toccata, ${ }^{12}$ a composition in free style written as a test and a display of the prowess of the musician, which in principle assumes artistic intuition and sensible reservation - a visceral knowledge of speeds and slownesses. Further to this, the in-directedness, or "towardness" of touch becomes clear when we realize that touching principally involves moving - we move in touching, we move to touch and, vice versa, we touch in moving and we touch to move-something that made Gilbert Simondon designate touch in terms of technique of a moving body, and thus of inescapable reshuffling its elements. Touch in this sense reflects properties of the mechanical body - the transistors, the chips, the software - that ensure the smooth transduction of information, thus animating the life of the code. We never touch anything, Simondon claims; we touch toward "the margin of indetermination" (1989, pp. 11-12). Placing touching in the in-between as a tending-toward, or becoming, makes it properly an act of entanglement, rather than a mere receptivity. The broader, aesthetic rendering of touch that expresses a quality of performance as touching attests to this complexity, which exceeds the unique abilities of the performer to include the qualities of the composition performed, the instrument on which it is performed, the venue in and occasion on which it is given, and a whole gamut of the more imperceptible and minute sensations. In a similar vein, digital devices and their interfaces have their own unique and specific touch - they feel a certain way. The haptic encounter reshuffles the perceptual elements of bodies and technologies that tend toward one another, revealing an immanent excess of sensibility, and thus a portal into extra-perceptual modes of sensory implications. To touch is not merely to receive sensory input; to touch is to produce, which expresses its unconscious and machinic formation.

"The Social Tree"- an interactive art installation commissioned for Terminal 1, and placed at the Central Piazza of Singapore's Changi International Airport in June 2013 - constitutes a relevant illustration of the environmental operation of the haptic unconscious of the code. Nine meters tall and eleven meters in diameter, the "Tree" has a trunk made up of 100 aluminum bars that uses LED lighting, producing an array of colors, and is topped with an animated crown, which is made up of 64 giant 42-inch high-definition screens. Altogether, the screens offer a 360-degree display of various animated backgrounds including, among others, a mystical forest, a deep sea environment, and the Singapore skyline. ${ }^{13}$ It is surrounded by eight touch-screen photo booths, equipped with haptic interface, which enable travelers to "attach" their photos onto the crown. As such, "The Social Tree" procedurally invites users to interact visually and haptically, which—read with Benjamin's critical vocabulary—reveals its taktisch character.

The word taktisch constitutes a kernel of the haptic unconscious, which expresses its machinic tactic of sensorial entanglement, and clearly points to its perceptual

12 In Italian toccata denotes the feminine of past participle of toccare, which means to touch.

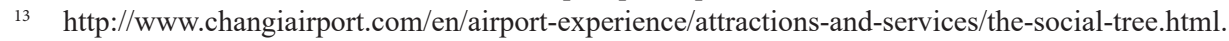


ambivalence. Aesthetically endowing sight with haptic richness, the taktisch mode of interaction with this artwork is additionally accentuated by the airport environment it is part of, which by virtue of its transitory nature, anticipatory management and dromological ambiance intensifies travelers' visual experience with eyes (almost) touching the surfaces like hands. Their aesthetic encounter with the image is not so much retinal anymore but taktisch, that is procedural. What we look at is not perceived in terms of closure as a final product, a reflected image, but becomes a haptic part of the visual procedure of serialization. The hands-on-screen procedure gives us a whole new experience of intimacy and togetherness, which may help us understand a peculiar sensation of warmth while we hold the glass-and-aluminum-made apparatuses in our hands or palpate them. It is not a form of crypto "haptocentrism", ${ }^{14}$ a post-Cartesian cultural tendency that gives precedence to touch over vision. The semantic ambiguity of the German term taktisch aptly conveys the shift away from traditional phenomenological account of sensation towards a non-anthropocentric and anthropomorphic, techno-intimate and extra-perceptual, (re-)arrangement ${ }^{15}$ of environmental sensibility. This is further intensified with a magic of Midas' touch operated by the code. As Maria Engberg observes, "The alluring and directly responsive interface hides of course high-tech machinery and while the promise is that of an immediate and immersive experience, it is nevertheless a mediated one" (2013, p. 23), and yetas she continues - "we are touching interfaces, perhaps even code, as we are touching glass after all" (ibid., p. 27). The intellectual tradition of representation along with its dualistic metaphysics has separated the code (the abstract) from its phenomenal perception (the concrete), and instilled us in thinking disjunctively with substances and appearances, decreeing that the code expresses itself only through intercessors. Put differently, we are culturally trained to think that the code needs, rather than is, a medium. Neither abstract nor concrete, the code is always already a discreet and creative coagulation of the sensible and the technical, and as such entangled with the sensory environment. Tactically ${ }^{16}$ generating a fruitful experiential ambiguity of the techno-sensorium, "The Tree" enmeshes the users into the codespace, which is borne out by the aesthetic sense of techno-intimacy, engendered by the haptic implication with the code. What you touch is (not) what you see.

As Wendy Hui Kyong Chun rightly puts it, "The computer - that most nonvisual and nontransparent device — has paradoxically fostered 'visual culture' and 'trans-

14 In his book On Touching. Jean-Luc Nancy, Jacques Derrida observes a shift in Western thinking after Descartes - a series of philosophies that award primacy to touch instead of sight. Furthermore, he identifies a specific branch thereof, i.e. "humanualism" [humainisme], which haunts Western philosophy and emphasizes the privileged status of the human species is determined by the touching hand $(2005$, p. 181).

15 Importantly, the term tactics - inherent in the German taktisch — derives from a Greek verb tassein, which means "arrange", or "handle". The phrase taktike techne stands for "art of arrangement". Its formative root also appears in touch.

16 That is: programmatically. 
parency" (2005, p. 2), which modern airport terminal has for decades exemplified in its architectural design and management of mobility. Nonetheless, the manner the interactive installation of "The Tree" works seems to dislodge, rather than strengthen, the transparency/opacity paradox that the airport codespace as a naturalized dimension of our airport environment resurfaces. The sensual economy of the airport is intensive, but on the phenomenological level, clearly, the visual dominates. The gradual digitization of the airport terminal has afforded greater manifestation of touch-based devices and mobilization of touching, which in effect has contributed to our consciousness of the code's opaque and invisible presence within, and transduction of, this space. The touchable screens notwithstanding, the predominant glass aesthetic of contemporary airport architecture alongside screen-based airport mediascapes conform to, and express, the superior principle of transparency, which ensures untroubled management, fluid securities procedure and smooth consumptive practice. Like every mediated technology, "The Social Tree" has its transparencies and opacities, but by visually-haptically tethering the airport sensory environment to the user's sensing body, it reveals illusory transparencies of the image, accentuating its generativity and contingency. Since it includes the reflection of the observer and their environment in its image, "The Social Tree" resists a virtually transparent view. It is no longer a numbing reflection and the narcotic power of represented image: ${ }^{17}$ the image technically acquires sensibility of its own, which haptically ignites movement of creation beyond the opacity of either the code or the mind. Far removed from an unconscious of automatic and programmatic immersion heralding a descent to alienation, hapticity activates machinic procedure of implication that - in lieu of a replication of established modes of perception - triggers our becoming-imperceptible. The more we touch, the less we see, yet, strangely enough, we feel visually enriched. Moving away from representation, the haptic screens in photo booths as a site of image generation turn into zones of procedural operation - the image becomes coupled into a single extra-perceptual system, an externalized body internalized as a natural interface. The transparency of the glassy surface - through haptic operation - operates a convergence between technical image and perceived image into forming an incorporeal double. The dialectic of transparent versus opaque is thus inadequate to the hybrid sensory airport, and in fact serves political interests of control and surveillance, which articulate — as Jean Baudrillard claims - "the fake transparency of the world to spread a terroristic confusion, to spread the germs or viruses of a radical illusion, that is to say operating a radical disillusion of the real. A viral and deleterious thought, which corrupts meaning, and is the accomplice of an erotic perception of reality's trouble" (1995).

17 In a chapter, tellingly titled, "The Gadget Lover", Marshall McLuhan analyzes the myth of Narcissus, drawing particular attention not so much to the event of falling in love with his reflected image, but emphasizing the peculiar hypnotic, or - as he puts it - "narcotic" charm and subsequent numbness that ultimately leads to Narcissus' drowning (1994, pp. 41-47). 


\section{En route: code's in-corporeality}

The airport codespace computationally envelops us, making us more and more intimately tied up with it. The reality of the code and the physical airport reality, including the bodies traveling through it as well as the social aereality, co(de)-entangle and amalgamate, thus evading the language of dualistic metaphysics of inside and outside, active and passive, motion and rest. As passengers increasingly engage with the sensory airport codespace through interactive surfaces that can algorithmically scan innumerable data of the passenger and identify hidden connections between people and networks for various purposes (e.g. security, mappable risk, commercial), Peter Sloterdijk's spherical approach, which accounts for entities and events that are not in front of us but that encircle and encompass us (2011), proves insufficient in that it does not place enough emphasis on the in-corporeal enmeshment of bodies and spaces. Rather, we are shrouded in the airport codespace, whose sentient apparatuses progressively insinuate into users' bodies. Unlike the classical airport architecture composed mainly of tubes as apparent extensions of the aircraft, that is supposed to prepare us for the processes and experience of jet flight, recently unveiled or renovated terminals or the ones just about to open resemble canyons-large and open halls in which light can flood down to the lower levels of the construction with various sensors and scanning devices often integrated into standard corridors in lieu of designated security areas to enhance and simplify the passenger experience. Rather than seduce and numb, today's airport design - attentive to the codespace processes and their mediascapes - is used to inspire and incite.

Crucially, contemporary airports are a relevant case in point to illuminate the increased efforts to strengthen tangibility in the human-machine interface through a whole new perception of bodies and surfaces (Gallace, Spence 2014, p. 229; Kasarda, Lindsay 2011). It must be noted that the traditional concept of interface expressive of an environment and a structural system that is formed of the physical machine, a virtual programming environment, and the user upholds the trenchant metaphysical binaries of subject - object, inside - outside, human - world, real - virtual. For this reason, Jordan Crandall chooses to leave it behind in favor of "gatherings"- sites of "affective transmission and absorption", which could be compared to what Alexander Galloway defines as a threshold, "a point of transition between different mediatic layers within any nested system" (2012, p. 31). Gallace and Spence in turn urge us to remember that "the most powerful interface ever designed between our self and the objects that surround us" is our own skin (2014, p. 19), ${ }^{18}$ a prototype of a digital screen. The airport codespace collapses orthodox representational models exposing

18 A systematic elaboration of skin as interface and its role in the development of a child is given by a French psychoanalyst Didier Anzieu. His notion of the skin ego is proposed to act as a unifying psychic envelope in accordance with the skin. As an interface, the skin ego is a kind of sensitive membrane that marks a boundary and simultaneously tethers us to the world, enabling all communication and exchange (2018). 
us as sensorially intertwined with it, neither inside nor outside, as immanent thresholds of becoming.

A sensorial meshwork emerges out of both the body's presence and the digital diffusion of that presence by rendering bodies as simulated and networked surfaces. Both the exuberance and variability of the artwork of "The Social Tree" created by touching the surface, and the psychophysical paradigm stating that it is only surface that can be touched evidently questions the conventional assumption of surfaces being superficial. It is the surface that attracts and stimulates most physical and chemical action - it is a site of affective transmission, absorption, attunement, ${ }^{19}$ and even reflection. "The Social Tree" mobilizes the idea of surface as a fold, a double fold entwining the code and the body and releasing an incorporeal double. Deleuze states, "It is by following the border, by skirting the surface, that one passes from bodies to the incorporeal" (2004, p. 12). He further explains,

[I]ncorporeal entities [...] are not physical qualities and properties [...] They are not things or facts, but events. We cannot say that they exist, but rather that they subsist or inhere ... They are not substantives or adjectives but verbs $[\ldots]$ the infinitives $[\ldots]$ incorporeal events $[\ldots]$ play only on the surface. (Ibid., pp. 7-8)

This engenders a new techno-intimate mode of extra-perceptual experience, properly in-corporeal enmeshment - the code anticipating the body, the body embodying the code. In no sense does the in-corporeal express the negative; conversely, it articulates that which vibrates and moves in perception but remains inaccessible to representation - the more-than-perceivable, the imperceptible. Deleuze rightly concludes, "If there is nothing to see behind the curtain, it is because everything is visible" (ibid., p. 12). Thus, touching and moving one another, the users and "The Tree", as well as the vaster codespace are, technically speaking, en route, always already on the surface and in the middle of something-journey, adventure, experience, exploration, becoming. As such, the sensory encounter necessarily involves a contraction, a simplification, abandonment, a meditation, ${ }^{20}$ generating a singular aesthetic of involution.

In this context, the installation of "The Social Tree" brings to mind the famous example of Cubist art - a series of four Cubist tree sculptures by the French twin sculptors Jan and Joël Martel_ exhibited, in collaboration with the architect Robert Mallet-Stevens, at the International Exposition of Decorative Arts Paris in 1925. In its emphasis on formal reduction and simplification as well as restrained set and economical use of materials, Cubism is an adequate illustration of the involutive

19 See chapter 7 "The Sense of a Subjective Self II: Affect Attunement”, Stern 1985.

20 The latter one can actually help us understand better both the mesmerizing and reductive power of these surfaces. Etymologically, the verb "surf" meaning to ride the surf, move on a wavy surface, comes from Polynesian cultures such as Hawai' ian, where the respective designate for surfing nalu derives from $n a$ [peace] and nalu [wave], in local culture actually denoting "meditation"-a sensible encounter of the bodies triggering their in-corporeal and involutive becoming. 
aesthetic that is apt to balance out the amount of means of expression to look elegant enough. Interestingly, the motif of a tree, also frequently reappears in the Stoic philosophy, ${ }^{21}$ which, as Deleuze points out, seems to have inspired Lewis Carroll's Alice's Adventures in Wonderland and, its sequel, Through the Looking-Glass (ibid., p. 12). Provoking an artistic scandal (as most of the Cubist works of painting and writing did upon release), the series of four trees, made of concrete, were nearly five meters high and had a cruciform trunk supporting quadrangular planes attached vertically and at angles, suggesting foliage or modern solar panels. ${ }^{22}$ In many respects "The Social Tree" reveals obvious Cubist influences-the multiple screens that shatter the representing power of subjective vision, the series of photo booths, amalgamated viewpoints of natural forms turn into a multifaceted surface of simplified geometrical planes, infinite becoming and transformation of the object, penchant for recombination and dynamic complexity, whose objective resides in fragmentation, defamiliarization and disidentification. Like the spectators of the exhibition who were consternated at, and deriding, the sight of natural forms reduced - in a Cubist spirit - to their geometrical equivalents, Alice of Wonderland lost her name in front of the tree. Users of "The Social Tree"- - haptically entangled with the apparatusmachinically create in-corporeal effects of sensation, thus becoming-imperceptible and extra-perceptually expanding their sensibility.

"Aviopolis", argue Fuller and Harley, "is a mix of multiple forms of life [...] As 'metastable' metaforms, airports mix multiple forms of life, matter and information into a series of new and constantly changing relations" (2004, pp. 104-105). Constantly upgrading, growing and changing due to intensive digitization, airports remain "metastable", that is "stable in their instability" (ibid., p. 114). The scale and speed of spreading of sensory media and their computational networks as well as their acquiescence to, and exploitation by, various regimes of control and consumption in the airport space evidently have been marginalizing (human) experience, rendering it increasingly dispersed, intangible and obsolete. As the airport codespace demonstrates, sensory data is meant to inform and incite, rather than explain; it points us toward understanding rather than knowledge which requires time, routinized sensible effort and curiosity. The problem, however, as the social dimension of "The Tree" unveils, is that we easily succumb to the seductive powers of sentient apparatuses and entrust them with a responsibility to guide our existence. Consequently, narcissism can be indulged and intensified without the terror of being out of touch or control. We need to understand the perceptual ambivalence of the sensory technologies and

21 The Stoics differentiated between two kinds of things, namely corporeal bodies and their incorporeal effects that are of an entirely different order and that express infinite, properly metaphysical events occurring at the surface of things, e.g. the tree greens as opposed to the green of a tree. See Deleuzee 2004, pp. 7-13.

22 These as well as "The Social Tree's" multiple screens clearly illustrate the Cubist breaking up of the form. 
their environmental expansion through the codespace. What we see may be a lot less then what we get.

\section{Bibliography}

Adey P., Aerial Life: Spaces, Mobilities, Affects, Oxford: Wiley-Blackwell, 2010.

Agamben G., What Is an Apparatus? And Other Essays, Stanford, CA: Stanford University Press, 2009.

Anzieu D., The Skin-Ego, transl. by N. Segal, New York: Routledge, 2018.

Augé M., The War of Dreams, transl. by L. Heron, London: Pluto, 1999.

Baudrillard J., "Radical Thought", Ctheory, 19 April 1995, http://www.ctheory.net/articles. aspx?id=67, accessed 4 January 2019.

Benjamin W., "The Work of Art in the Age of Mechanical Reproduction", in: W. Benjamin, Illuminations: Essays and Reflections, transl. by H. Zohn, New York: Schocken, 1969, pp. 217-252.

Berleant A., Living in the Landscape: Toward an Aesthetics of Environment, Lawrence: University Press of Kansas, 1997.

Berleant A., Sensibility and Sense: The Aesthetic Transformation of the Human World, Exeter: Imprint Academic, 2010.

Budd L.C.S., Adey P., "The Software-Simulated Airworld: Anticipatory Code and Affective Aeromobilities", Environment and Planning A 2009, no. 41, pp. 1366-1385.

Chun W.H.K., "On Software, or the Persistence of Visual Knowledge", Grey Room 2005, no. 18 , pp. 26-51.

Crandall J., "Summary of Gatherings", http://jordancrandall.net/main/+GATHERINGS/index.html, accessed: 4 January 2019.

Deleuze G., Nietzsche and Philosophy, New York: Columbia University Press, 1983.

Deleuze G., The Logic of Sense, transl. by M. Lester with Ch. Stivale, London: Continuum, 2004.

Deleuze, G., Guattari F., Anti-Oedipus, transl. R. Hurley, M. Seem, H.R. Lane, London: Continuum, 2004a.

Deleuze G., Guattari F., A Thousand Plateaus, transl. by B. Massumi, New York: Continuum, 2004b.

Deleuze, G., Parnet C., Dialogues II, transl. by H. Tomlinson, B. Habberjam, London: Continuum, 2006.

Derrida J., On Touching. Jean-Luc Nancy, transl. by Ch. Irizarry, Stanford: Stanford University Press, 2005.

Engberg M., "Performing Apps Touch and Gesture as Aesthetic Experience", Performance Research: A Journal of the Performing Arts 2013, vol. 5, no. 18, pp. 20-27.

Fuller G., Harley R., Aviopolis: A Book about Airports, London: Black Dog Publishing, 2004.

Gallace A., Spence Ch., In Touch with the Future: The Sense of Touch from Cognitive Neuroscience to Virtual Reality, Oxford: Oxford University Press, 2014.

Galloway A., The Interface Effect, London: Polity, 2012.

Goodman S., Sonic Warfare: Sound, Affect, and the Ecology of Fear, Cambridge: MIT Press, 2010. 
Gordon A., Naked Airport: A Cultural History of the World's Most Revolutionary Structure, New York: Metropolitan Books, 2004.

Guattari F., The Machinic Unconscious: Essays in Schizoanalysis, transl. by T. Adkins, Los Angeles: Semiotext(e), 2011.

Howes D., "Hyperaesthesia, or the Sensual Logic of Late Capitalism", in: Empire of the Senses, ed. by D. Howes, Oxford: Berg, 2005, pp. 281-303.

Huhtamo E., "Twin - Touch - Test - Redux: Media Archeological Approach to Art, Interactivity, and Tactility", in: Media Art Histories, ed. by O. Grau, Cambridge: MIT Press, 2007, pp. 73-74.

Kasarda J.D., Lindsay G., Aerotropolis: The Way We'll Live Next, New York: Farrar, Straus and Giroux, 2011.

Kerckhove D. de, “Touch versus Vision”, in: Die Aktualität des Ästhetischen, ed. by W. Welsch, Münich: Wilhelm Fink Verlag, 1993, pp. 135-168.

Kitchin R., Martin D., Code/Space: Software and Everyday Life, Cambridge: MIT Press, 2011.

Mayer-Schönberger V., Cukier K., Big Data: A Revolution That Will Transform How We Live, Work and Think, London: John Murray Publishers, 2013.

McLuhan M., Understanding Media: The Extension of Man, Cambridge: MIT Press, 1994.

Montagu A., Touching: The Human Significance of the Skin, New York: Harper \& Row, 1986.

Munster A., An Aesthesia of Networks: Conjunctive Experience in Art and Technology. Cambridge: MIT Press, 2013.

Nancy J.-L., Noli Me Tangere: On the Raising of the Body, transl. by S. Clift, P.-A. Brault, M. Naas, New York: Fordham University Press, 2008.

Nye D.E., Technology Matters: Questions to Live with, Cambridge: MIT Press, 2006.

Paterson M., The Senses of Touch: Haptics, Affects and Technologies, Oxford: Berg, 2007.

Sadin É., La societé de l'anticipation, Paris: Éditions inculte, 2011.

Simondon G., Du Mode d'existence des objets techniques, Paris: Aubier, 1989.

Sloterdijk P., Bubbles. Spheres I, New York: Semiotext(e), 2011.

Schmidt E., Cohen J., The New Digital Age: Reshaping the Future of People, Nations and Business, New York: Knopf, 2013.

Stern D., The Interpersonal World of the Infant, New York: Basic Boks, 2000.

Weiser M., "The Computer for the $21^{\text {st }}$ Century", Scientific American 1991, no. 265(3), pp. 94-110. 